$\underline{\text { Review Article }}$

\title{
JANUS KINASE ENZYME (JAK) INHIBITORS AND RHEUMATOID ARTHRITIS: A REVIEW OF THE LITERATURE
}

\author{
AYMAN ASKARI ${ }^{1}$, ABDULLA KHALID NOURI ${ }^{2}$, HANA MORRISSEY ${ }^{3}$, PATRICK A. BALL ${ }^{3}$ \\ ${ }^{1}$ The Robert Jones and Agnes Hunt Orthopaedic Hospital NHS Foundation Trust, SY10 7AG, United Kingdom, ${ }^{2}$ Department of Medicine \\ Jordan Hospital Amman, Queen Noor Street, Jordan, ${ }^{3}$ University of Wolverhampton, School of Pharmacy, WV1 1LY, United Kingdom \\ Email: hana.morrissey@wlv.ac.uk
}

Received: 15 Aug 2019, Revised and Accepted: 10 Oct 2019

\begin{abstract}
Cytokines play an essential role in normal cell growth and the regulation of immune function. The emergence of Janus Kinase Enzyme inhibitors promises the start of a revolution in the treatment of several chronic diseases. Their efficacy and safety profile have been demonstrated in multiple trials and they have been licensed for the treatment of a number of diseases including RA and PsA. Moreover, the use of highly selective Janus Kinase Enzyme inhibitors is currently being studied aiming to reduce side effects compared with traditional JAKinibs, an example of that would be the recent FDA approved upadacitinib. The Janus Kinase Enzyme inhibitorsmay supplant the classical biologic agents in the treatment of autoimmune diseases, since they exhibitthe advantages of oral administration, simultaneous blockade of multiple cytokines, reversibility and the lack of immunogenicity.
\end{abstract}

Keywords: Cytokines, Janus Kinase Enzyme Inhibitors, JAKinibs, Rheumatoid Arthritis

(C) 2019 The Authors. Published by Innovare Academic Sciences Pvt Ltd. This is an open access article under the CC BY license (http://creativecommons.org/licenses/by/4.0/) DOI: http://dx.doi.org/10.22159/ijcpr.2019v11i6.36343

\section{INTRODUCTION}

Cytokines play an essential role in normal cell growth and the regulation of immune function. Moreover, the role of cytokines in the pathophysiology of various autoimmune diseases and malignancies has become well established in recent years. As a result, the targeting of cytokines has become an attractive mechanism for developing drugs that may alter the course of such diseases. ${ }^{1}$ Janus Kinase Enzyme inhibitors (JAKinibs) are a novel class of drugs used mainly in the treatment of autoimmune diseases and haematologic malignancies.

JAK is a type of tyrosine kinase enzyme, it is part of a cytokine signaling pathway known as the Janus kinase/signal transducer and activator of transcription (JAK/STAT) signaling pathway, used mainly by types I/II cytokine signaling receptors [1,2].

Cytokines were first targeted with the emergence of monoclonal antibodies. Monoclonal antibodies also known as 'biologic' agents, target the cytokines outside of the cell by blocking the cytokine itself, or its receptor. ${ }^{3}$ On the other hand, JAKinibs work inside the cell to block the intracellular signaling pathway, and thus are able to block the activity of multiple pro-inflammatory cytokines simultaneously $[1,2,4]$.

The first JAKinibs licensed for use in clinical practice was Ruxolitinib ${ }^{2}$. It has been used in the treatment of haematologic malignancies such asmyelofibrosis and polycythemiavera. Tofacitinib and baricitinib are also approved by the United States of America Food and Drug Administration (FDA) for the treatment of Rheumatoid Arthritis (RA), whiletofacitinib is approved for the treatment of psoriatic arthritis (PsA) and ulcerative colitis (UC). ${ }^{1}$ Other JAKinibis (table 1) are currently undergoing different phases of clinical trials ${ }^{1}$, including a promising JAK 1 selective inhibitor Upadacitinib, which has been recently FDA approved for the treatment of rheumatoid arthritis (RA) $[5,6]$.

Table 1: Showing some of the current JAKinibis $[1,2,7-9]$

\begin{tabular}{|c|c|c|c|}
\hline $\begin{array}{l}\text { Generic name (Brand } \\
\text { name) }\end{array}$ & $\begin{array}{l}\text { JAK } \\
\text { selectivity }\end{array}$ & Example of cytokines inhibited & Use \\
\hline Ruxolitinib (Jakavi) & JAK1, JAK2 & IL-6, EPO, IFN & Myelofibrosis, polycythemia vera \\
\hline Tofacitinib (Xeljanz) & JAK1, JAK3 & $\begin{array}{l}\text { Common gamma chain cytokines (IL- } \\
2,4,7,8,15,21 \text { ), IFN- } \gamma \text {, IL- } 6\end{array}$ & Rheumatoid arthritis, psoriatic arthritis, ulcerative colitis \\
\hline Baricitinib (Olumiant) & JAK1, JAK2 & Gamma chain cytokines, IL-6, GM-CSF, IFN- $\gamma$ & Rheumatoid arthritis \\
\hline Upadacitinib (Rinvoq) & JAK 1 & IL-6, IFN- $\gamma$ & $\begin{array}{l}\text { Rheumatoid arthritis (approved), psoriatic arthritis, } \\
\text { ulcerative colitis, Crohn's disease, atopic dermatitis, giant } \\
\text { cell arteritis }\end{array}$ \\
\hline
\end{tabular}

\section{Mechanism of action}

Over 50 different cytokines including interferons, interleukins, colony stimulating factors and hormones bind to type I and type II cytokine receptors. This superfamily of receptors utilizes the action of the JAK in order to transduce the signal into the nucleus with the help of the STAT protein. There are four known types of the intracellular enzyme JAK (JAK 1, 2, 3, TYK2) [10]. When a specific cytokine binds to its corresponding type I/II receptor, the receptor first undergoes a conformational change, this recruits the JAK enzymes and then phosphorylates them. This is a key event in signal transduction, as the phosphorylation of the JAKs triggers their enzymatic activity. The phosphorylated JAK transfers a phosphate group from ATP to specific residues on cytokine receptors (fig. 1) [11].

The next step depends on the STAT protein, which comprises the second part of the JAK-STAT pathway. The phosphorylated residues on the receptors act as docking sites for the STAT proteins. The phosphorylated STAT proteins dimerize and head towards the nucleus to trigger or modify gene transcription [12]. JAKinibs, 
reversibly bind to the ATP binding pockets of the JAKs and thus inhibit phosphorylation of the tyrosine residues, thereby inhibiting their enzymatic activity, and as a result inhibit the whole process of downstream signaling (fig. 1) [1].

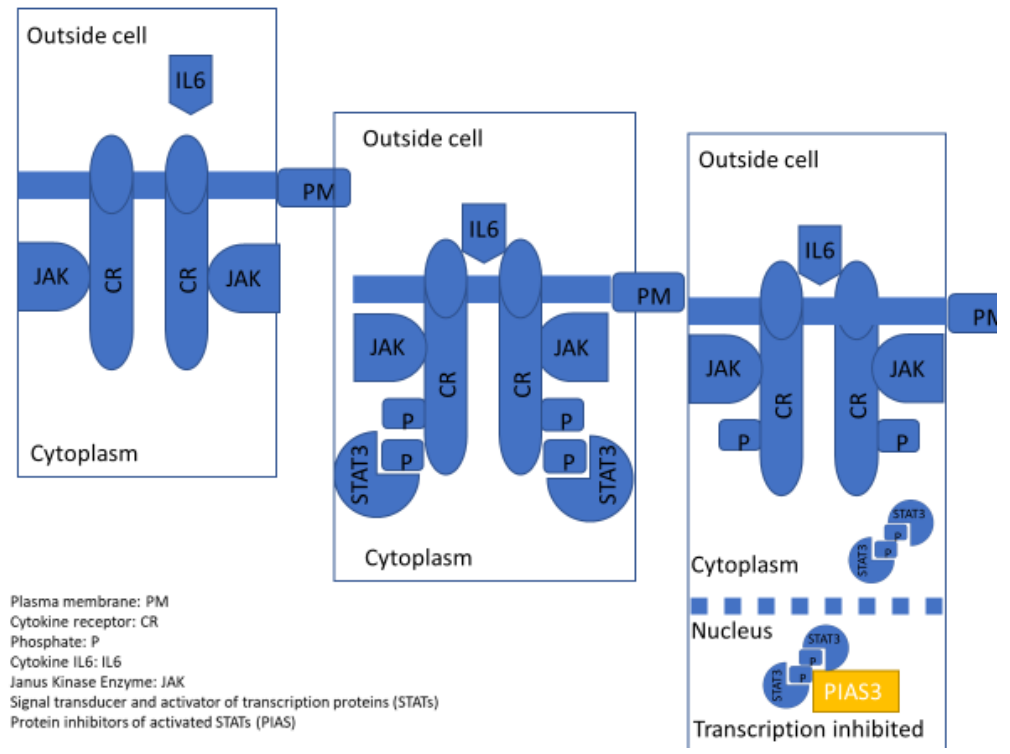

Fig. 1: Key steps of the JAK-STAT pathway

\section{Trials}

Several clinical trials have been conducted using JAKinibis and many more are ongoing of note arethree recently published trials, summarised below:

1. RA-BEAM is a phase 3, double blind, placebo and active controlled trial by Eli Lilly ${ }^{\mathrm{TM}}$ and Incyte ${ }^{\mathrm{TM}}$ involved participants with active RA receiving background methotrexate (MTX). The participants were randomly assigned to a placebo group, baricitinib or adalimumab. All patients received background MTX [13, 14]. The study concluded that "in patients with rheumatoid arthritis who had experienced an inadequate response to methotrexate, baricitinib was associated with significant clinical improvements as compared with placebo and adalimumab "[14].

2. OPAL BROADEN a phase 3 , double-blind, active controlled, placebo-controlled trial by Pfizer ${ }^{T M}$ involved participants with active psoriatic arthritis who had inadequate response to conventional synthetic disease-modifying antirheumatic drugs (csDMARDs) [15, 16]. The participants were assigned to tofacitinib, adalimumab or a placebo group. The study concluded that "the efficacy of tofacitinib was superior to that of placebo at month 3 in patients with psoriatic arthritis who had previously had an inadequate response to conventional synthetic DMARDs"[16].

3. SELECT COMPARE by Abbvie ${ }^{\mathrm{TM}}$ is a phase 3, randomized, doubleblind study, comparing upadacitinib to placebo and adalimumab, in patients with active RA with inadequate response to MTX. The study concluded that upadacitinib was superior to placebo and adalimumab in terms of improvement of RA signs, symptoms and physical function in the MTX inadequateresponders' population. Moreover, radiographic progression was markedly lower with upadacitinib compared to placebo. The safety profile of upadacitinib was similar to that of adalimumab, except for an increased risk of herpes zoster infection and elevated Creatine Phosphokinase (CPK) levels in upadacitinib $[5,17]$.

\section{Advantages of JA kinibs}

The main advantage of JAKinibs over biologic disease modifying anti rheumatic drugs (bDMARDs) is the fact that JAKinibs can be administered orally, as they are made up of small molecules, whereas biologic agents, are made of larger molecules and are administered as injections or as infusions. However, one could argue that in some patients, parenteral administration of a drug may ensure maximum compliance [18]. In addition to that, JAKinibs when compared to bDMARDshave the advantage of targeting multiple cytokines at once ${ }^{9}$, and reversibility of binding to their targetsuch that, theoretically speaking, their effects can be rapidly reversed for example in the event of infections or pre-operatively $[8,18]$.

Furthermore, biologic agents with repetitive administration maytrigger an immune response against them resultingin the production of Auto Drug Antibodies (ADAs) which may neutralizetheir effects $[19,20]$. This ultimately causes a secondary lack of efficacy and may alter pharmacologic properties of the bDMARDs. $[4,19,20]$ This is not seen with JAKinibs [21].

\section{Adverse effects of JA kinhibs}

As cytokines are essential for normal immune function, cellular growth, and bone marrow function, inhibiting their functions may produces predictable side effects related to the physiological processes. These include but are not limited to: increased risk of development of infections, anemia, leukopenia, hyperlipidemia, increased cardiovascular disease risk, gastrointestinal perforation and malignancies (table 2) [10].

Table 2: Showing side effects encountered with olumiant (Baricitinib) $4 \mathrm{mg}$ once daily for $16 \mathrm{w}$ (Data taken from 6 placebo-controlled studies) [22]

\begin{tabular}{lll}
\hline Very common $(\mathbf{1 / 1 0})$ & Common $(\mathbf{1} / \mathbf{1 0 0}$ to $<\mathbf{1 / 1 0})$ & Uncommon $(\geq \mathbf{1} / \mathbf{1 , 0 0 0}$ to $<\mathbf{1} / \mathbf{1 0 0})$ \\
\hline URTI & Herpes zoster, Herpes simplex, & Neutropenia \\
& Gastroenteritis, Urinary tract infections & \\
Hypercholesterolemia & Thrombocytosis & Hypertriglyceridemia \\
& Nausea & Acne \\
& ALT increased $\geq 3 \times$ upper limit of normal & AST increased $\geq 3 \times$ upper limit of normal \\
& & Weight increased \\
& Creatine phosphokinase increased $\geq 5 \times$ upper limit of normal \\
\hline
\end{tabular}


Blocking signal transmission by the inhibition of JAK has potentially serious implications. Tofacitinib's safety profile has been studied in multiple trials. At clinically approved doses, it appears generally well tolerated and has a similar safety profile to that of bDMARDs, apart from an increased risk of viral infections (herpes zoster). However, Tofacitinib has a relatively short half-life ( $3 \mathrm{~h}$ ) compared to bDMARDs, thus in case of a severe infection, the drug can be withheld and the immunosuppressive effect rapidly eliminated [1, 23, 24]. More serious side effects such as the occurrence of malignancies are possible because Tofacitinib inhibits signalling by IL-2 and IL-15 which are important for the differentiation and activation of Natural Killer cells [12]. A serious adverse event reported with the use of baricitinib is the increased risk of thrombosis; deep vein thrombosis and pulmonary embolism as well as arterial thrombosis. Extra caution should be taken when prescribing baricitinib in patients with a raised risk of thrombosis [25].

\section{Recommendations for RA}

According to the American College of Rheumatology (ACR) guideline and the recommendations of the European League against Rheumatism (EULAR), treatment for RA should be initiated with methotrexate (MTX). If disease control isn't achieved with MTX monotherapy plus a short trial of glucocorticoids, the ACR guidelines recommend the use of either a combination of conventional synthetic Disease modifying anti rheumatic drugs (csDMARD), a biologic DMARD (bDMARD)+/-MTX, or Tofacitinib+/-MTX. The combination of tofacitinib+/-MTX may be considered as an alternative inbDMARD-refractory RA patients.[26]The EULAR suggest consideration of the addition of either tofacitinib or baricitinib to the treatment regimen of MTX inadequate responders or bDMARD inadequate responders in patients with RA [26].

For the treatment of PsA, Tofacitinib has been approved for use in the United States and the European Union, where it is indicated for use in combination with MTX in patients who have not had adequate response to therapy or those that have been intolerant to previous therapy with DMARDs [27].

\section{Monitoring protocol}

In general, prior toinitiation of treatmentwith JAKinibs, patients should be screened for viral hepatitis and latent tuberculosis (TB). Anti-TB treatment should be considered in patients who have untreated latent TB. Patients should also have a baselinecomplete blood count performedprior to the initiation of treatment and (importantly $\mathrm{Hb}$, absolute neutrophil, lymphocyte count, platelets), liver and kidney function test at baseline, plus a lipid profile. Also, measuring blood pressure and heart rate at baselineis recommended, and a periodic examination of skin in patients at increased risk of skincancer. Patients should be up to date with their immunisations and live vaccines should be avoided during treatment with JAKinibs [22-24].

\section{CONCLUSION}

The emergence of JAK inhibitors promises the start of a revolution in the treatment of various chronic diseases. Their efficacy and safety profile hasbeen demonstrated in multiple trials and JAKinibs have been licensed for the treatment ofa number of diseases including RA and PsA. Moreover, the use of highly selective JAKinibs is currently being studied aiming to reduce side effects compared with traditional JAKinibs. An example of that would be the recently FDA approved upadacitinib $[1,6]$. It remains to be seen whether the JAKinibs will replace the classical biologic agents in the treatment of autoimmune diseases, but they hold some clear advantages; oral administration, blockade of multiple cytokines simultaneously, reversibilityand the lack of immunogenicity $[4,8,18-20]$.

\section{AUTHORS CONTRIBUTIONS}

All the author have contributed equally

\section{CONFLICT OF INTERESTS}

\section{Declared none}

\section{REFERENCES}

1. T Virtanen A, Haikarainen T, Raivola J. Selective JAKinibs: prospects in inflammatory and autoimmune diseases. BioDrugs 2019;33:15.
2. Furumoto $Y$, Gadina M. The arrival of JAK inhibitors: advancing the treatment of immune and hematologic disorders. BioDrugs 2013;27:431-8.

3. Peleg Rider, Yaron Carmi, Idan Cohen. Biologics for targeting inflammatory cytokines, clinical uses, and limitations. Int J Cell Biol 2016:11. https://doi.org/10.1155/2016/9259646.

4. Kotyla PJ. Are Janus kinase inhibitors superior over classic biologic agents in RA patients? Biomed Res Int 2018. Doi:10.1155/2018/7492904

5. Fleischmann R, Pangan AL, Mysler E, Bessette L, Peterfy C, Durez $\mathrm{P}$, et al. A phase 3, randomized, double-blind study comparing upadacitinib to placebo and to adalimumab, in patients with active rheumatoid arthritis with inadequate response to methotrexate. Arthritis Rheumatol 2018;70 (Suppl 10). https://acrabstracts.org/abstract/a-phase-3-randomizeddouble-blind-study-comparingupadacitinib-to-placebo-and-toadalimumab-in-patients-with-active-rheumatoid-arthritis-

withinadequate-response-to-methotrexate/. [Last accessed on 24 Aug 2019]

6. FDA Approves Upadacitinib (Rinvoq), New JAK Inhibitor for RA-Medscape; 2019.

7. Upadacitinib. AbbVie. Available from: https://www.abbvie.com/ourscience/pipeline/upadacitinib.html. [Last accessed 24 Aug 2019]

8. Choy EH. Clinical significance of Janus Kinase inhibitor selectivity [published correction appears in rheumatology (Oxford). Rheumatology (Oxford). 2019;58:953-62.

9. Salvatore Bellinvia, Christopher J Edwards. JAK Inhibitors in the treatment algorithm of rheumatoid arthritis: a review. E Med J Rheumatol 2018;5:59-65.

10. Schwartz, Daniella M. JAK inhibition as a therapeutic strategy for immune and inflammatory diseases. Nat Rev Drug Discovery 2017;17:78.

11. O'Shea JJ, Schwartz DM, Villarino AV, Gadina M, McInnes IB, Laurence A. The JAK-STAT pathway: impact on human disease and therapeutic intervention. Annu Rev Med 2015;66:311-28.

12. Yoshiya Tanaka. Recent progress and perspective in JAK inhibitors for rheumatoid arthritis: from bench to bedside. J Biochem 2015;158:173-9.

13. Clinical Trials. gov. Bethesda (MD): National Library of Medicine (US). 2000 Feb 29. Identifier (NCT01710358), a study in moderate to severe rheumatoid arthritis (RA-BEAM); 2017. p. $15 . \quad$ Available from: https://clinicaltrials.gov/ct2/show/NCT01710358?term=rabeamandrank=1 [Last accessed on 02 May 2019]

14. Taylor PC. Baricitinib versus placebo or adalimumab in rheumatoid arthritis. New England J Med 2017;376:652-62.

15. ClinicalTrials.gov. Bethesda (MD): National Library of Medicine (US). 2000. Identifier (NCT01877668), efficacy and safety of tofacitinib in psoriatic arthritis: comparator study (OPAL BROADEN); $2017 . \quad$ Available from: https://clinicaltrials.gov/ct2/show/NCT01877668 [Last accessed on 02 May 2019]

16. Mease P. Tofacitinib or adalimumab versus placebo for psoriatic arthritis. New England J Med 2017;377:1537-50.

17. Fleischmann R, Pangan AL, Song IH. Upadacitinib versus placebo or adalimumab in patients with rheumatoid arthritis and an inadequate response to methotrexate: results of a phase 3, double-blind, randomized controlled trial. Arthritis Rhematol 2019;71:1788-800.

18. Mocsai A. What is the future of targeted therapy in rheumatology: biologics or small molecules? BMC Med 2014;12:43.

19. Wolf Henning Boehncke, Nicolo Costantino Brembilla. Immunogenicity of biologic therapies: causes and consequences. Expert Rev Clin Immunol 2018;14:6, 513-23.

20. Puig L, Gulliver W. Adverse reactions to biologics. Curr Probl Dermatol Basel Karger 2018;53:37-48.

21. George E Fragoulis, Iain B McInnes, Stefan Siebert, JAK-inhibitors. New players in the field of immune-mediated diseases, beyond rheumatoid arthritis. Rheumatology 2019;58:i43-i54.

22. Olumiant (baricitinib) tablets. Summary of Product Characteristics. Eli Lilly and Company Ltd; 2017. Available from: https://www.ema.europa.eu/en/documents/product- 
information/olumiant-epar-product-information_en.pdf [Last accessed on 02 Jul 2019].

23. Xeljanz/XeljanzXR (tofacitinib) [prescribing information]. New York, NY: Pfizer; 2018. Available from: https://www. accessdata.fda.gov/drugsatfda_docs/label/2018/203214s018l bl.pdf [Last accessed on 02 Jul 2019].

24. Xeljanz (tofacitinib) [product monograph]. Kirkland, Quebec, Canada: Pfizer Canada ULC; 2019. Available from: https://www.pfizer.ca/sites/default/files/201902/XELJANZ_P M_E_222743_04Feb2019.pdf [Last accessed on 02 Jul 2019].
25. Important safety information for Olumiant (baricitinib) tablets. Eli Lilly and Company Ltd 2018.

26. Peter C Taylor. Clinical efficacy of launched JAK inhibitors in rheumatoid arthritis. Rheumatology 2019;58:i17-i26.

27. Paik J, Deeks ED. Tofacitinib: a review in psoriatic arthritis. Drugs 2019;79:655.

28. Cutolo M. The kinase inhibitor tofacitinib in patients with rheumatoid arthritis: latest findings and clinical potential. Ther Adv Musculoskelet Dis 2013;5:3-11. 